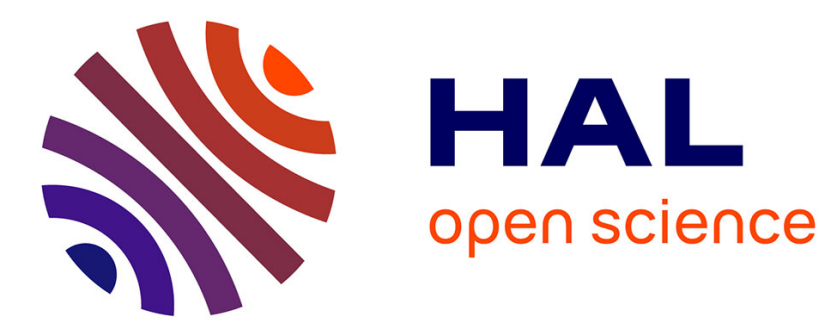

\title{
Magnetic Anisotropy and Phase Transitions in Co-Doped Yttrium Iron Garnet Films
}

\author{
M. Tekielak, W. Andrä, A. Maziewski, J. Taubert
}

\section{To cite this version:}

M. Tekielak, W. Andrä, A. Maziewski, J. Taubert. Magnetic Anisotropy and Phase Transitions in Co-Doped Yttrium Iron Garnet Films. Journal de Physique IV Proceedings, 1997, 07 (C1), pp.C1461-C1-462. 10.1051/jp4:19971188 . jpa-00254837

\section{HAL Id: jpa-00254837 https://hal.science/jpa-00254837}

Submitted on 1 Jan 1997

HAL is a multi-disciplinary open access archive for the deposit and dissemination of scientific research documents, whether they are published or not. The documents may come from teaching and research institutions in France or abroad, or from public or private research centers.
L'archive ouverte pluridisciplinaire HAL, est destinée au dépôt et à la diffusion de documents scientifiques de niveau recherche, publiés ou non, émanant des établissements d'enseignement et de recherche français ou étrangers, des laboratoires publics ou privés. 


\title{
Magnetic Anisotropy and Phase Transitions in Co-Doped Yttrium Iron Garnet Films
}

\author{
M. Tekielak, W. Andrä*, A. Maziewski and J. Taubert* \\ Institute of Physics, Warsaw University Branch, Lipowa 41, 15-424 Bialystok, Poland \\ * Institut fuir Physikalische Hochtechnologie Jena, Helmholtzweg 4, 07743 Jena, Germany
}

\begin{abstract}
YIG:Co,Ca, Ge films grown on (001) plane substrate were investigated down to liquid helium temperatures using torque anisometry technique. Successively lowering temperature spin-reorientational transitions were observed between following easy magnetization axes (EMA) orientations: (i) at room temperature - four EMA inclined to the film plane from [111] directions; (ii) two EMA near the [110] and [1 10] directions; (iii) two other EMA near the [100] and [010] directions; (iv) one EMA near the [001] direction at the helium temperature.
\end{abstract}

The garnet YIG:Co, $\mathrm{Ca}, \mathrm{Ge}$ films have been intensively investigated at room temperature because of their interesting magnetic and magnetooptical properties [1,2]. Knowledge of temperature dependence of magnetic anisotropy in these samples is very important for understanding of recent results of investigation of photomagnetic effects $[3,4]$ or peculiarities of FMR signal [5,6].

$\mathrm{Y}_{3-2} \mathrm{Ca}_{2} \mathrm{Fe}_{5-x-y} \mathrm{Co}_{x} \mathrm{Ge}_{y} \mathrm{O}_{12}$ films were grown by liquid phase epitaxy on (001) plane gadolinium gallium garnet GGG substrate. The films were prepared in a form of a disk with diameter of $4 \mathrm{~mm}$ and thicknesses of $7 \div 10 \mu \mathrm{m}$. The measurements were carried out in the temperature region from liquid helium temperature to room temperature by means of an automatic torquemeter. The period of magnetic field rotation was $6 \mathrm{~min}$. Torque curves were measured in three characteristic planes: (001), (100) and (110) (examples are shown in Fig.1). The contribution of the paramagnetic GGG substrate was determined by measuring the torque as a function of field amplitude. This contribution was numerically subtracted from the total torque.

The analysis of the curves, obtained in this way, displays the orientation of easy magnetization axes. One can distinguish several temperature ranges of different EMA orientation. Four axes EMA $\mathrm{E}_{11}$ (inclined from the [111]-type directions to the sample plane) were found (Fig.1A) at the room temperature. One of these axes can be described by the angles $54.7^{\circ}<\vartheta_{111}<\frac{\pi}{2}, \phi_{111}=\frac{\pi}{4}(\vartheta, \phi$ are polar and azimuthal angles measured in the $x, y, z$ co-ordinate system connected with the standard [100], [010] and [001] crystallographic axis). With decreasing temperature an increase of $\vartheta_{111}$ was observed. Lowering of the temperature a transition to the configuration with two easy axes $\mathrm{EMA}_{110}$ (near [110] and [1 $\left.\overline{1} 0\right]$ ) took place see Fig.2. Further lowering of the temperature induced the following EMA configurations: (i) the EMA $\mathrm{E}_{100}$ oriented near [100] and [010]; (ii) the EMA $\mathrm{A}_{001}$ near [001]. Temperature range of coexistence of the $\mathrm{EMA}_{110}, \mathrm{EMA}_{100}$ and EMA $\mathrm{A}_{001}$ configurations depends on small difference of sample chemical composition. Only the EMA001 configuration was observed at the helium temperature.

The EMA reorientation could be discussed in the simple case, taking into consideration $K_{c 1}, K_{u}$ - first constants describing cubic and uniaxial anisotropy. For different values of these constants, different EMA orientation could be found out, as follow:

(1) $\mathrm{EMA}_{001} \quad \mathrm{~K}_{\mathrm{cl}}<0 ; \mathrm{K}_{\mathrm{u}} /\left|\mathrm{K}_{\mathrm{cl}}\right|<-0.5\left\{\vartheta_{001}=0\right\}$;

(2) $\mathrm{EMA}_{11} \quad-0.5<\mathrm{K}_{\mathrm{u}} /\left|\mathrm{K}_{\mathrm{cl}}\right|<1 \quad\left\{\vartheta_{111}=\arcsin \sqrt{\frac{2}{3}\left(1-\frac{\mathrm{K}_{\mathrm{u}}}{\left|\mathrm{K}_{\mathrm{cl}}\right|}\right)} ; \quad \phi_{111}=\frac{\pi}{4}, \frac{3}{4} \pi, \frac{5}{4} \pi, \frac{7}{4} \pi\right\}$;

(3) $\mathrm{EMA}_{110} \quad 1<\mathrm{K}_{\mathrm{u}} /\left|\mathrm{K}_{\mathrm{c} 1}\right| \quad\left\{\vartheta_{110}=\frac{\pi}{2} ; \phi_{110}=\frac{\pi}{4}, \frac{3}{4} \pi, \frac{5}{4} \pi, \frac{7}{4} \pi\right\}$;

(4) $\mathrm{EMA}_{001} \quad K_{\mathrm{cl}}>0 ; K_{\mathrm{u}} / K_{\mathrm{cl}}<1 \quad\left\{\vartheta_{001}=0\right\}$;

(5) $\mathrm{EMA}_{100} \quad-1<\mathrm{K}_{\mathrm{u}} / \mathrm{K}_{\mathrm{cl}} \quad\left\{\vartheta_{100}=\frac{\pi}{2} ; \phi_{100}=0, \frac{\pi}{2}\right\}$ 


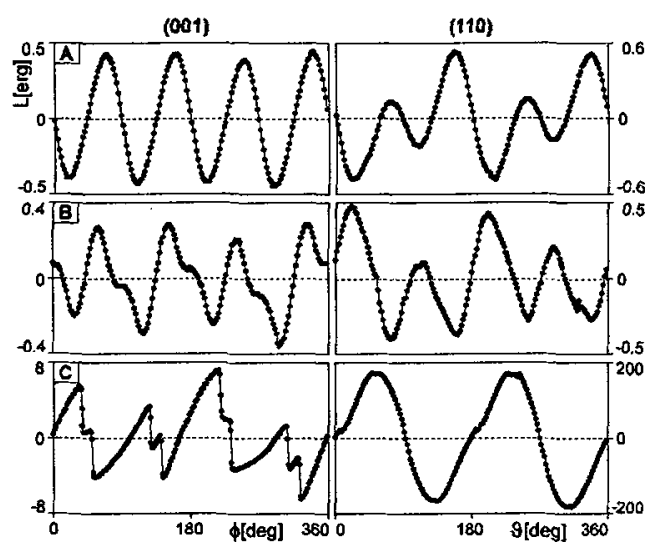

Figure 1: Exemplary torque curves measured for two planes (001) and (110) at the temperature T: (A) $290 \mathrm{~K}$; (B) $140 \mathrm{~K}$; (C) $10 \mathrm{~K} . \mathrm{H}=10 \mathrm{kOe}$ external magnetic field was applied.

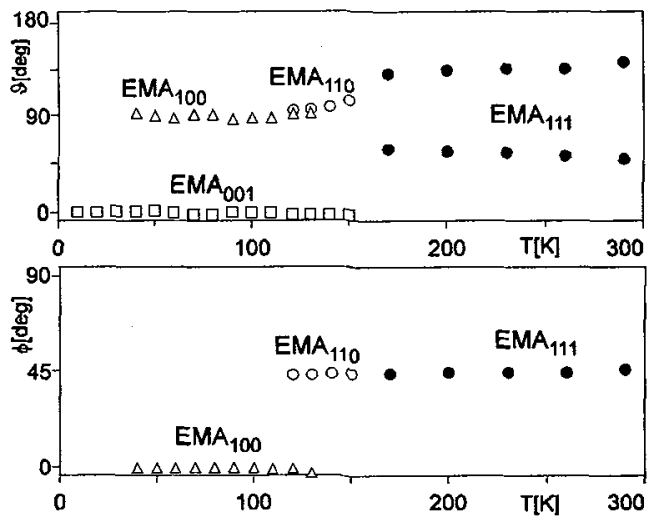

Figure 2: Diagram of easy magnetization axis orientation versus temperature.

Using this simple model we cannot explain the coexistence of EMA $\mathrm{A}_{110}$ and $\mathrm{EMA}_{001}$ configurations even taking into account $\mathrm{K}_{\mathrm{c} 2}$ [7]. Three cubic anisotropy and two uniaxial anisotropy constants were used for description of low temperature torque curves measured in our samples [8].

At room temperature the first cubic anisotropy constant fulfills the relation $K_{\mathrm{cl}}<\mathrm{K}_{\mathrm{cl} \text { YYG }}<0$, where $\mathrm{K}_{\mathrm{cl} \text { YIG }}$ is first anisotropy constant measured for pure YIG sample [9]. Huge contribution to cubic anisotropy was reported [9] for $\mathrm{Co}_{0}^{2+}$ and $\mathrm{Co}_{\mathrm{t}}^{3+}$ ions in the octahedral and tetrahedral positions, respectively. At room temperature $\mathrm{Co}_{\mathrm{t}}^{3+}$ ions contribution to cubic anisotropy is larger than $\mathrm{Co}_{0}^{2+}$ one. However, for decreasing temperature one can expect [9] a stronger contribution of $\mathrm{Co}_{0}^{2+} . \mathrm{The} \mathrm{EMA}_{11]}$ $\rightarrow$ EMA $_{110}$ transition may be explained assuming an increase of the ratio $K_{u} /\left|K_{c l}\right|$ connected with an increasing contribution of $\mathrm{Co}_{0}^{2+}$ to the cubic anisotropy. The transition $\mathrm{EMA}_{110} \rightarrow \mathrm{EMA}_{100}, \mathrm{EMA}_{\infty 01}$ can be also connected with $\mathrm{Co}_{0}^{2+}$ ions, for which [110] is the hard magnetization axis [10].

Lowering temperature the increase of $\vartheta_{111}$ angle and the transition $E M A_{111} \rightarrow E_{110}$ could be also deduced analyzing hysteresis loops, which were measured using magnetooptical set-up [11]. The observed deviation of the measured $\vartheta_{110}$ from the theoretically predicted $\pi / 2$ may be explained assuming a deviation of the [001] axis from the film normal. Such deviation is also the reason for the asymmetry observed in hysteresis loops, self biasing effect [1].

\section{Acknowledgments}

The authors are grateful to Prof. P. Görnert for initiation of preparation and study of YIG films and his great interest and support of these investigations.

The work was partially supported by the Polish grant 2P03B 16809.

\section{References}

[1] Maziewski A., J.Magn.Magn.Mat. 88 (1990) 325 and references there in.

[2] Maziewski A., "Domain structure stabilization processes in a magnet with magnetization induced anisotropy", The Sixth International Conference on Ferrites (ICF 6), Tokyo 29 Sept. - 2 Oct. 1992, T. Yamaguchi, M. Abe, (Ferrites Proceedings of the ICF 6, Japan 1992) pp. 782-788.

[3] Maryško M., IEEEE Trans. on Magn. 22 (1994) 978.

[4] Chizhik A.B., Lyakhimets S.N., Maziewski A. and Tekielak M., JMMM 140-144 (1995) 2111.

[5] Rudov S.G., Verchenko M.V., Veselago V.G., Maziewski A., Tekielak M., Lyakhimets S.N. and Desvignes J.M., IEEE Trans.Magn. 30 (1994) 791.

[6] Jabłoński R., Maziewski A., Tekielak M. and Desvignes J.M., J.Magn.Magn.Mat., to be published.

[7] Maziewski A., Babicz Z. and Murtinová L., Acta Phys.Pol. A72 (1987) 811.

[8] To be published.

[9] Hansen P., Enke K. and Winkleer G., Landolt-Bornstein, Numerical Data and Functional Relationships in Science and Technology, group III: vol. 12, part a (Springer-Verlag, Heidelberg, New York 1978).

[10] Hansen P., Tolksdorf W. and Krishman R., Phys.Rev. B 16, 9 (1977) 3973.

[11] Kisielewski M., Lichtchenko O. and Maziewski A., J.Magn.Magn.Mat. 101 (1991) 213. 